\title{
Penggunaan Media Sosial di Kalangan Mahasiswa Selama Pandemi Covid-19
}

\author{
Aldina Eka Andriani ${ }^{1}$ Sri Sulistyorini ${ }^{2}$ \\ ${ }^{1}$ Pendidikan IPA, Universitas Negeri Semarang \\ Email: aldinaekaandriani@gmail.unnes.ac.id \\ 2 Pendidikan IPA, Universitas Negeri Semarang \\ Email: srisulistyyorini@gmail.unnes.ac.id
}

\begin{abstract}
Social media is one of the tools used to support the lecture process during the COVID-19 pandemic. The purpose of this research is to find out the use of social media among students during online lectures. This research was conducted online by distributing questionnaires to PGSD students of the Faculty of Education, Semarang State University semester 2, 4, and 6 of the 2019/2020 Academic Year. The sample technique used is the Slovin formula with a tolerance of $1 \%$ so that as many as 851 students are obtained from 919 students. The questionnaire made in the form of a google form was given to the sample. The results showed that students used social media for more than 2 years (97.2\%), long before the pandemic. Whatsapp is the most widely used social media, which is $99.6 \%$ by students, Instagram $98 \%$ and Youtube $87.2 \%$. Social media is used to find various information (91.4\%), to communicate (64.6\%), and to eliminate boredom $62.1 \%$
\end{abstract}

Keywords : Social Media, Online Lecture, Covid-19

Abstrak. Media sosial menjadi salah satu sarana yang digunakan dalam menujang proses perkuliahan di masa pandemi covid-19. Tujuan peneltian ini adalah mengetahui penggunaan media sosial di kalangan mahasiswa selama perkuliahan daring. Penelitian ini dilakukan secara daring dengan menyebar kuesioner pada mahasiswa PGSD Fakultas IImu Pendidikan Universitas Negeri Semarang semester 2, 4, dan 6 Tahun Akademik 2019/2020. Teknik sampel yang digunakan menggunakan rumus Slovin dengan toleransi 1\% sehingga didapatkan sebanyak 851 mahasiswa dari 919 mahasiswa. Kuesioner yang dibuat dalam bentuk google form yang diberikan kepada sampel. Hasil penelitian menunjukkan bahwa mahasiswa menggunakan media sosial lebih dari 2 tahun (97,2\%), jauh sebelum adanya pandemi. Whatsapp menjadi media sosial yang paling banyak digunakan yaitu sebesar 99,6\% oleh mahasiswa, Instagram 98\% dan Youtube 87,2\%. Media sosial digunakan untuk menemukan berbagai informasi (91,4\%), untuk berkomunikasi (64,6\%), dan menghilangkan kejenuhan 62,1\%.

Kata Kunci : Media Sosial; Perkuliahan Daring; Covid-19

\section{PENDAHULUAN}

Diumumkannya oleh Organisasi Kesehatan Dunia (WHO) pada 11 Maret 2020 wabah Coronavirus Disease 2019 (Covid-19) menjadi pandemi membuat hampir seluruh sektor terdampak. Kondisi tersebut mengakibatkan perubahan yang luar biasa di seluruh sektor di muka bumi, termasuk pendidikan. Di Indonesia, sejak pemerintah mengumumkan kasus pertama Covid-19 pada bulan Maret 2020, pemerintah melalui Kementerian Pendidikan dan Kebudayaan (Kemendikbud) telah menetapkan kebijakan learning from home atau belajar dari rumah (BDR) terutama wilayah yang berada di zona kuning, orange dan merah. Hal ini seolah-olah seluruh jenjang pendidikan 'dipaksa' untuk dapat bertransformasi agar dapat beradaptasi secara cepat untuk melakukan proses pembelajaran di rumah melalui media daring (online). 
Dengan adanya pembatasan aktivitas selama pandemi Covid-19 maka aktivitas perlahan dilakukan secara online, salah satunya dalam dunia pendidikan. Peniadaan aktivitas perkuliahan secara tatap muka dapat digantikan dengan perkuliahan online agar proses kegiatan belajarmengajar tetap berjalan (Purwanti \& Krisnadi, 2020). Saat ini, dengan meningkatnya akses ke teknologi, mahasiswa dapat menggunakan berbagai bentuk media sosial dalam menambah pengetahuan. Penggunaan teknologi digital memungkinkan proses pembelajaran dapat berjalan meskipun mahasiswa dan dosen yang berada di tempat yang berbeda (Milman, 2015).

Perubahan kebiasaan perkuliahan ini tidak serta merta tanpa permasalahan. Menurut (Kusnayat et al., 2020), perubahan metode pembelajaran dengan cara klasikal dan tatap muka menjadi metode online mendapatkan berbagai reaksi dari mahasiswa. Lebih lanjut, Dewantara \& Nurgiansah (2020) menjelaskan bahwa $79 \%$ mahasiswa menginginkan pembelajaran secara tatap muka.

Kebijakan akan proses pembelajaran sepenuhnya dilakukan di rumah secara daring mengakibatkan waktu yang digunakan mahasiswa dalam menggunakan perangkat elektronik seperti smartphone dan komputer akan lebih banyak. Selain mengakses media pembelajaran yang telah disediakan oleh pihak kampus, tentu tidak dapat dipungkiri penggunaan media sosial juga meningkat. Seiring penggunaan teknologi yang pesat, tentunya perlu dibarengi dengan kesadaran agar memberikan dampak yang positif bagi seluruh penggunanya.

Menurut Kaplan \& Haenlein (2010), media sosial adalah teknologi yang memungkinkan komunikasi virtual dan berbagi ide dengan mudah dan efisien. Berbagai macam plafform media sosial yang saat ini popular seperti Instagram, Facebook, Youtube, Twitter, dan lain-lain. Saat ini, penggunaan media sosial oleh para mahasiswa semakin meluas setiap harinya (Kenny \& Johnson, 2016) .

Dengan krisis pandemi saat ini, pendidikan di seluruh dunia beralih ke pembelajaran jarak jauh. Namun, dengan adanya situs jejaring sosial, para peserta didik dapat beradaptasi dengan mudah dengan tenaga pendidik untuk proses pembelajaran ataupun sekedar bertukar ide dan kolaborasi sosial yang lebih baik. Selain itu, dapat membuat proses pembelajaran lebih fleksibel, membantu siswa berinovasi dengan ide-ide baru, dan memfasilitasi pembelajaran komunal dengan saling berkolaborasi. Namun, beberapa penelitian berspekulasi bahwa media sosial dapat berdampak negatif pada siswa, sebagian mereka mungkin bisa membuat ketagihan (yaitu, menghabiskan waktu berjam-jam di media sosial) dan menyebabkan gangguan (Hou et al., 2019; Kuss \& Griffiths, 2017).

Penelitian ini mencoba untuk menggali informasi mengenai penggunaan media sosial di kalangan mahasisa PGSD UNNES. Hal yang dikaji mencakup informasi tentang waktu menggunakan media sosial, media sosial yang paling sering digunakan, berapa lama waktu yang mereka habiskan dalam mengakses media sosial serta tujuan dan motivasi menggunakan media sosial.

\section{METODE PENELITIAN}

Penelitian ini menggunakan pendekatan metode survei dengan sifat deskriptif yang memiliki tujuan untuk menggambarkan keadaan atau fenomena yang terjadi (Arikunto, 2011). Responden penelitian adalah mahasiswa Progran Studi Sekolah Dasar (PGSD) Fakultas IImu Pendidikan Universitas Negeri Semarang yang berstatus aktif pada semester Genap Tahun Akademik 2019/2020.

Survei dilakukan secara online melalui google form. Populasi dalam penelitian ini yaitu mahasiswa PGSD semester 2, 4 dan 6 Tahun Akademik 2019/2020 yang berjumlah 919 mahasiswa. Pemilihan sampel menggunakan metode random sampling, sampel yang terpilih secara acak tanpa membedakan jenis kelamin dan semester. Kemudian dalam menentukan jumlah sampel yang akan diambil pada penelitian ini menggunakan rumus Slovin dengan batas toleransi 1\%, sehingga didapatkan jumlah sampel dalam penelitian ini adalah 851 mahasiswa. Peneliti menggunakan teknik analisis data kuantitatif dengan pendekatan deskriptif. Menggunakan penghitungan skor dari masing-masing jawaban. 
Pengumpulan data menggunakan alat ukur berupa lembar kuesioner (angket) yang telah disusun secara terstrukur mengenai bermedia sosial pada mahasiswa selama mengikuti perkuliahan daring dalam bentuk google form. Aspek-aspek yang ditanyakan dalam penelitian ini adalah: (1) Sejak kapan menggunakan media sosial; (2) media sosial apa saja yang digunakan selama ini; (3) latar belakang menggunakan media sosial; (4) media sosial yang digunakan setiap hari; (5) durasi waktu yang digunakan dalam menggunakan media sosial; dan (6) manfaat menggunakan media sosial.

\section{HASIL PENELITIAN DAN PEMBAHASAN}

\section{a. Hasil Penelitian}

Penelitian ini dilakukan di Program Studi Pendidikan Guru Sekolah Dasar Fakultas Ilmu Pendidikan Unnes. Teknik pengambilan sampel menggunakan rumus Slovin dengan batas toleransi $1 \%$, sehingga diperoleh sampel sebanyak 851 mahasiswa.

Tabel 1. Distribusi Frekuensi Mahasiswa PGSD UNNES Berdasarkan Jenis Kelamin

\begin{tabular}{clcc}
\hline No. & Jenis Kelamin & Frekuensi (f) & Persentase (\%) \\
\hline 1. & Laki-laki & 119 & 14 \\
\hline 2 & Perempuan & 732 & 86 \\
\hline & Jumlah & $\mathbf{8 5 1}$ & $\mathbf{1 0 0}$
\end{tabular}

Berdasarkan tebel 1 menunjukkan bahwa responden yang mengikuti penelitian didominasi oleh perempuan sebanyak 732 orang (86\%) dan laki-laki sebanyak 119 orang (14\%). Untuk mengetahui penggunaan media sosial selama perkuliahan daring pada mahasiswa, peneliti mengajukan beberapa pertanyaan yang sangat relevan untuk diisi secara jujur oleh responden yang secara sukarela mau mengisi kuesioner yang telah disiapkan. Berikut ini beberapa pertanyaan yang diajukan kepada responden:

1. Sejak kapan Anda menggunakan media sosial?

Pertanyaan ini diajukan untuk melihat waktu menggunakan media sosial di kalangan mahasiswa. Berikut hasil survei terhadap waktu penggunaan media sosial bagi mahasiswa:

Tabel 2. Waktu menggunakan media sosial di kalangan mahasiswa

\begin{tabular}{cccc}
\hline No. & Waktu & Jumlah & Persentase \\
\hline 1 & $<1$ Bulan & 2 & $0,2 \%$ \\
\hline 2 & $<6$ Bulan & 2 & $0,2 \%$ \\
\hline 3 & $<1$ Tahun & 3 & $0,3 \%$ \\
\hline 4 & $<2$ Tahun & 18 & $2,1 \%$ \\
\hline 5 & $>2$ Tahun & 827 & $97,2 \%$ \\
\hline
\end{tabular}

Berdasarkan Tabel 2 tentang penggunaan media sosial di kalangan mahasiswa mengatakan bahwa sebanyak 827 orang mahasiswa $(97,2 \%)$ menggunakan media sosial lebih dari 2 tahun terakhir, sebanyak 18 orang mahasiswa $(2,1 \%)$ menggunakan media sosial sejak 2 tahun terakhir ini, sebanyak 3 orang mahasiswa $(0,3 \%)$ menggunakan media sosial 1 tahun terakhir ini, dan sebanyak 2 orang mahasiswa (0,2\%) menggunakan media sosial dalam kurung waktu 6 dan 1 bulan terakhir ini.

2. Media sosial apa saja yang Anda gunakan selama ini?

Pertanyaan ini diajukan untuk mengetahui aplikasi media sosial yang paling banyak digunakan selama pandemi covid-19. Berikut hasil survei terhadap aplikasi media sosial yang digunakan selama pandemi covid-19. 


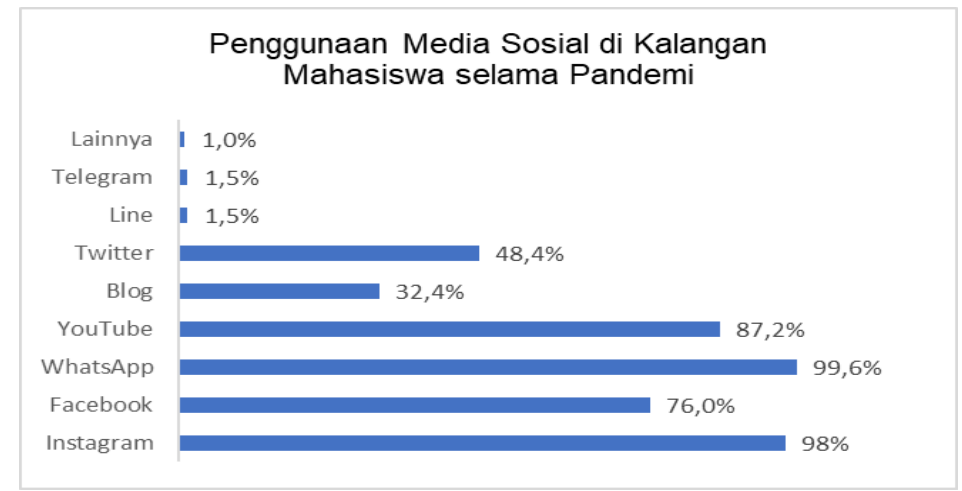

Gambar 1. Media sosial yang digunakan mahasiswa

Berdasarkan gambar 1 diatas didapatkan bahwa aplikasi Whatsapp merupakan media sosial yang paling banyak digunakan yaitu sebesar $99,6 \%$, aplikasi Instagram merupakan media sosial kedua yang paling banyak digunakan oleh mahasiswa yaitu sebesar $98 \%$, aplikasi Youtube menjadi media sosial ketiga yang paling banyak digunakan oleh mahasiswa sebesar $87,2 \%$, aplikasi Facebook menjadi media sosial keempat yang paling banyak digunakan oleh mahasiswa yaitu sebesar $76 \%$, aplikasi Twitter digunakan mahasiswa sebesar $48,4 \%$, penggunaan blog bagi mahasiswa sebesar $32,4 \%$, dan aplikasi Telegram dan Line masing-masing sebesar $1,5 \%$ serta aplikasi media sosial lain sebesar $1 \%$.

3. Apa latar belakang Anda menggunakan media sosial?

Pertanyaan ini diajukan untuk mengetahui latar belakang dari mahasiswa menggunakan media sosial. Berikut hasil survei terhadap latar belakang penggunaan media sosial bagi kalangan mahasiswa.

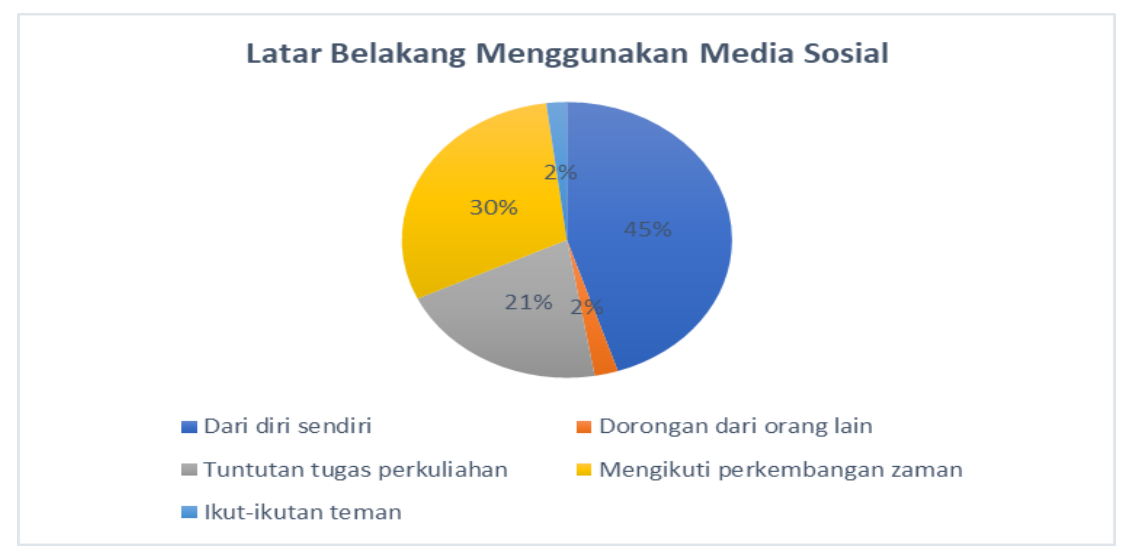

Gambar 2. Latar Belakang menggunakan Media Sosial

Berdasarkan gambar 2, didapatkan hasil bahwa faktor yang paling dominan yang menjadi latar belakang menggunakan media sosial di kalangan mahasiswa berasal dari diri sendiri yaitu sebesar $45 \%$ atau sebantar 383 mahasiswa. Faktor mengikuti perkembangan zaman diurutan kedua yaitu sebesar $30 \%$ atau sebesar 255 orang responden. Adanya tuntutan tugas perkuliahan sebesar $21 \%$, dan faktor dari dorongan orang lain serta sekedar ikut-ikutan menggunakan media sosial masingmasing sebesar $2 \%$.

4. Media sosial apa saja yang Anda gunakan setiap hari?

Pertanyaan ini diajukan untuk mengetahui media sosial yang sering diakses oleh para mahasiswa. Berikut hasil survei mengenai media sosial yang digunakan setiap hari. 


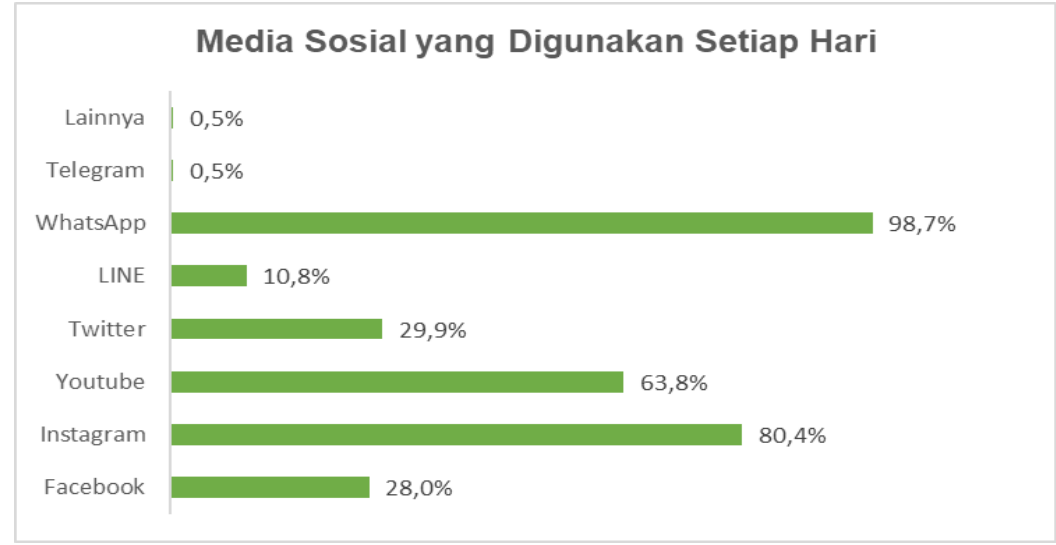

Gambar 3. Media sosial yang digunakan setiap hari

Berdasarkan gambar 3 didapatkan hasil bahwa aplikasi whatsapp merupakan media yang paling banyak digunakan oleh mahasiswa setiap harinya yaitu sebesar $98,7 \%$, aplikasi Instagram sebesar $80,4 \%$, aplikasi youtube sebesar $63,8 \%$, aplikasi twitter sebesar $29,9 \%$, aplikasi facebook sebesar $28 \%$, dan aplikasi line dan telegram masing-masing sebesar $10,8 \%$ dan $0,5 \%$.

5. Berapa waktu yang Anda gunakan untuk mengakses media sosial dalam sekali membuka aplikasi tersebut?

Pertanyaan ini diajukan untuk mengetahui waktu yang digunakan mahasiswa dalam mengakses media sosial dalam sekami membuka aplikasinya. Berikut hasil survei mengenai durasi penggunaan media sosial.

Tabel 3. Durasi penggunaan media sosial

\begin{tabular}{cccccccccc}
\hline & \multicolumn{4}{c}{ Frekuensi penggunaan media sosial } & \multicolumn{7}{c}{ Durasi Waktu } \\
\cline { 2 - 10 } & $\begin{array}{c}\text { Setiap } \\
\text { saat }\end{array}$ & $\begin{array}{c}3-4 \text { kali } \\
\text { sehari }\end{array}$ & $\begin{array}{c}1-2 \text { kali } \\
\text { sehari }\end{array}$ & $\begin{array}{c}\text { Tidak } \\
\text { mengakses } \\
\text { setiap hari }\end{array}$ & $\begin{array}{c}\text { Lebih } \\
\text { dari } 5\end{array}$ & $\begin{array}{c}3-5 \\
\text { jam }\end{array}$ & $\begin{array}{c}2-3 \\
\text { jam }\end{array}$ & $\begin{array}{c}1-2 \\
\text { jam }\end{array}$ & $\begin{array}{c}\text { Kurang } \\
\text { dari 1 } \\
\text { jam }\end{array}$ \\
\hline \multirow{2}{*}{ Jumlah } & $57,5 \%$ & $30,5 \%$ & $10,7 \%$ & $1,3 \%$ & $21,4 \%$ & $15,7 \%$ & 16,5 & 27,9 & 18,5 \\
\hline
\end{tabular}

Berdasarkan tabel 3 didapatkan hasil bahwa frekuensi pengunaan media sosial pada mahasiswa cenderung mengakses media sosial setiap saat sebesar 57,5\%, 3-4 kali sehari sebesar $30,5 \%$, frekuensi $1-2$ kali sehari sebesar $10,7 \%$ dan tidak mengakses media sosial setiap hari sebesar 1,3\%. Kemudian, terkait dengan waktu yang digunakan mahasiswa setiap mengakses media sosial secara berurutan yaitu paling banyak selama 1-2 jam yaitu sebesar 27,9\%, waktu akses lebih dari 5 jam sebesar 21,4\%, waktu akses kurang dari 1 jam sebesar 18,5\%, waktu akses 2-3 jam sebesar $16,5 \%$ dan waktu akses 3-5 jam sebesar 15,7\%.

6. Apa manfaat yang Anda rasakan dari penggunaan media sosial?

Pertanyaan ini diajukan untuk mengetahui manfaat media sosial bagi mahasiswa. Berikut ini hasil survei mengenai manfaat dari penggunaan media sosial. 


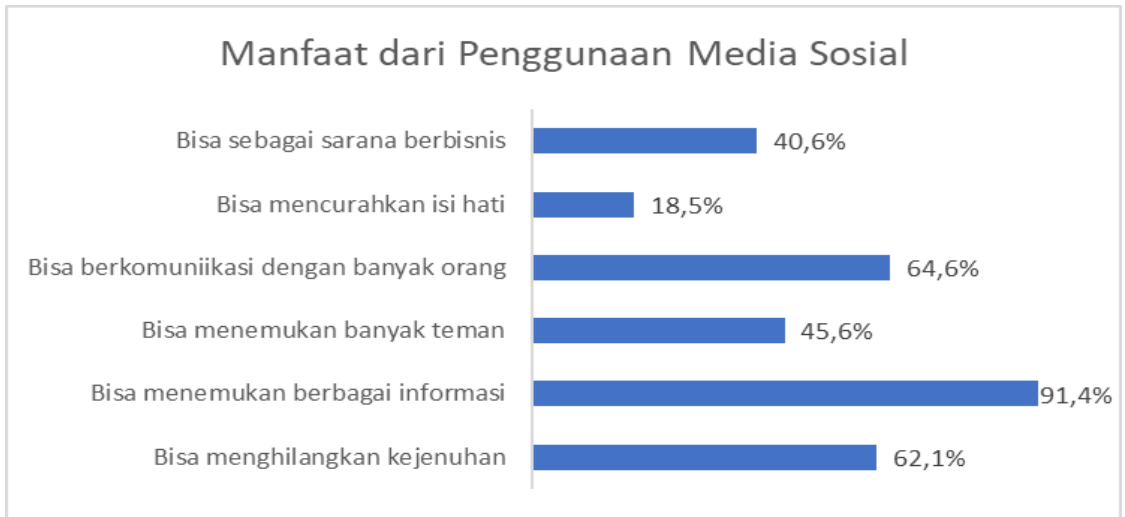

Gambar 4. Manfaat penggunaan media sosial bagi mahasiswa

Berdasarkan gambar 4 diatas didapatkan hasil yaitu manfaat media sosial bisa menemukan berbagai informasi sebesar $91,4 \%$, media sosial digunakan berkomunikasi dengan banyak orang sebesar $64,6 \%$, media sosial digunakan untuk menghilangkan kejenuhan sebesar $62,1 \%$, media sosial digunakan untuk menemukan banyak teman sebesar $45,6 \%$, media sosial digunakan sebagai sarana berbisnis yaitu sebesar $40,6 \%$, dan media sosial digunakan sebegai tempat mencurahkan isi hati sebesar $18,5 \%$.

\section{b. Pembahasan}

Penelitian dilakukan kepada mahasiswa aktif yang melaksanakan pembelajaran pada semester genap tahun akademik 2019/2020 yaitu mahasiswa semester II, IV dan IV dengan jumlah responden 815 orang. Keseluruhan mahasiswa yang bersedia mengisi kuesioner menyatakan telah melaksanakan pembelajaran daring tahun akademik 2019/2020.

Menurut Triastuti, Endah, dan Dimas Adrianto, (2017) bahwa penduduk Indonesia yang telah menggunakan media sosial mencapai 106 juta jiwa dari total populasi 262 juta jiwa. Dalam penelitian lain oleh (Saputra, 2019) menujukkan bahwa sebanyak 97\% mahasiswa mengaku sebagai pengguna aktif media sosial. Oleh karena itu sebagai mana dijelaskan dalam tabel 2 sebanyak 97,2\% mahasiswa telah menggunakan media sosial lebih dari 2 tahun yang lalu. Hal tersebut menujukkan bahwa penggunaan media sosial dikalangan mahasiswa jauh sebelum adanya pandemi covid-19.

Aplikasi WhatsApp merupakan media sosial yang paling banyak digunakan oleh kalangan mahasiswa (gambar 1) sebesar 99,6\% mahasiswa mengaku sebagai pengguna aplikasi WhatsApp. Hasil tersebut tidak jauh berbeda dengan penelitian Saputra (2019) yang menunjukkan bahwa sebear 95,96\% mahasiswa sebagai pengguna WhatsApp. Hal yang sama dalam Status Literasi Digital Indonesia 2020, WhatsApp menjadi media sosial favorit masyarakat Indonesia yaitu sebesar $98,9 \%$ (Center, 2020). Sementara itu, dalam penelitian ini aplikasi Instagram dan Youtube menjadi media sosial yang paling banyak diakses setelah WhatsApp yaitu masing-masing $98 \%$ dan $87,2 \%$ responden (gambar 1).

Dilihat dari latar belakang menggunakan media sosial pada kalangan mahasiswa (gambar 2), sebagian besar responden (45\%) berasal dari diri sendiri, dalam artian tanpa paksaan oleh pihak manapun. Selain itu, menggunakan media sosial bagi mahasiswa merupakan bentuk dalam mengikuti perkembangan zaman (30\%), dan juga adanya tuntutan tugas perkuliahan (21\%) yaitu pengumpulan tugas melalui media sosial.

Dilihat dari penggunaan media sosial yang digunakan setiap hari oleh kalangan mahasiswa (gambar 3), WhatsApp merupakan aplikasi yang paling banyak digunakan oleh mahasiswa yaitu sebesar $98,7 \%$, kemudian diurutan kedua terdapat Instagram sebesar $80,4 \%$ dan Youtube diurutan ketiga sebesar $63,8 \%$.

Dilihat dari waktu penggunaan media sosial, sebagian besar responden mengakses media sosial setiap saat $(57,5 \%)$, artinya responden tidak mengalokasikan waktu khusus untuk mengakses media sosial. Responden yang mengakses media sosial sebanyak 3-4 kali dalam sehari sebesar 30,5\% 
dan sebanyak $10,7 \%$ responden hanya akan mengakses media sosial dalam 1-2 kali dalam sehari, serta terdapat $1,3 \%$ responden yang tidak mengakses media sosial setiap hari (tabel 3 ). Hal senada yang dikemukanan Saputra (2019) bahwa sebagian besar responden mengakses media sosial setiap saat yaitu sebesar $81 \%$. Sementara itu, sebagian besar waktu yang dihabiskan responden setiap kali mengakses media sosial antara 1-2 jam (tabel 2). Lebih lanjut dalam penelitian Saputra (2019) menunjukkan bahwa besaran waktu yang digunakan mengakses media sosial antara 1-6 jam sehari. Diperkuat pula dalam laporan (Center, 2020), menyatakan bahwa rata-rata pengguna media sosial di Indonesia menghabiskan waktu selama 7 jam 59 menit.

Pemanfaatan media sosial bagi kalangan mahasiswa sebagian besar digunakan dalam menemukan berbagai informasi sebesar $91,4 \%$. Selain itu, media sosial dimanfaatkan untuk berkomunikasi dengan banyak orang oleh $64,6 \%$ responden, serta dengan bermedia sosial diyakini dapat menghilangkan kejenuhan oleh $62,1 \%$ responden. Media sosial pula dapat dimanfaatkan untuk menemukan banyak teman, sebagai sarana berbisnis serta digunakan sebagai tempat mencurahkan isi hati. Hasil ini berbeda dengan penelitian (Rajeh et al., 2020) bahwa media sosial digunakan paling banyak untuk hiburan oleh $81,4 \%$ responden.

\section{KESIMPULAN}

Berdasarkan hasil dan pembahasan di atas dapat disimpulan bahwa sebagian besar responden telah menggunakan media sosial lebih dari 2 tahun yang lalu. Hal ini menujukkan bahwa mahasiswa menggunakan media sosial jauh sebelum adanya pandemi covid-19 ini. Sebagian besar mahasiswa menggunakan media sosial atas dasar diri sendiri (45\%) dan mengikuti perkembangan zaman (30\%) serta penggunaan media sosial digunakan atas dasar tuntutan tugas perkuliahan (21\%). Platform media sosial WhatsApp merupakan media sosial yang paling banyak digunakan mahasiswa yaitu $99,6 \%$, Instagram (98\%), Youtube $87,2 \%$.

Mahasiswa memanfaatkan media sosial hampir setiap saat (lebih dari 5 kali sehari) dengan rata-rata durasi penggunaan media sosial setiap kali akses selama 1-2 jam dengan kata lain durasi akses media sosial lebih dari 5 jam setiap hari. Pemanfaatan media sosial paling banyak untuk menemukan informasi $(91,4 \%)$.

\section{DAFTAR PUSTAKA}

Arikunto, S. (2011). Prosedur Penelitian: Suatu Pendekatan Praktik (Rev VI). Rineka Cipta.

Center, K. I. (2020). Status Literasi Digital Indonesia: Hasil Survei di 34 Provinsi (Issue November).

Dewantara, J. A., \& Nurgiansah, T. H. (2020). Efektivitas Pembelajaran Daring di Masa Pandemi COVID 19 Bagi Mahasiswa Universitas PGRI Yogyakarta. Jurnal Basicedu, 5(1), 367-375.

Hou, Y., Xiong, D., Jiang, T., Song, L., \& Wang, Q. (2019). Social Media Addiction: Its Impact, Mediation, and Intervention. Cyberpsychology: Journal of Psychosocial Research on Cyberspace, 13(1).

Kaplan, A. M., \& Haenlein, M. (2010). Users of the world, unite! The challenges and opportunities of Social Media. Business Horizons, 53(1), 59-68.

Kenny, P., \& Johnson, I. G. (2016). Social media use, attitudes, behaviours and perceptions of online professionalism amongst dental students. British Dental Journal, 221(10), 651-655.

Kusnayat, A., Muiz, M. hifzul, Nani, S., Mansyur, A. salim, \& Zaqiah, Q. yulianti. (2020). Pengaruh Teknologi Pembelajaran Kuliah Online Di Era Covid-19 Dan Dampaknya Terhadap Mental 
Mahasiswa. EduTeach : Jurnal Edukasi Dan Teknologi Pembelajaran, 1(2), 153-165.

Kuss, D. J., \& Griffiths, M. D. (2017). Social networking sites and addiction: Ten lessons learned. International Journal of Environmental Research and Public Health, 14(3), 1-17.

Milman, N. B. (2015). Distance Education. In International Encyclopedia of the Social \& Behavioral Sciences: Second Edition (Second Edi, Vol. 6). Elsevier.

Purwanti, E., \& Krisnadi, I. (2020). Implementasi Sistem Perkuliahan Daring Berbasis ICT Dalam Masa Pandemi Wabah Covid -19. Pascasarjana Program Magister Teknik Elektro Universitas Mercu Buana, 1(1), 1-12.

Rajeh, M. T., Sembawa, S. N., Nassar, A. A., Al Hebshi, S. A., Aboalshamat, K. T., \& Badri, M. K. (2020). Social media as a learning tool: Dental students' perspectives. Journal of Dental Education, 85(4), 1-8.

Saputra, A. (2019). Survei Penggunaan Media Sosial Di Kalangan Mahasiswa Kota Padang Menggunakan Teori Uses and Gratifications. Baca: Jurnal Dokumentasi Dan Informasi, 40(2), 207-216.

Triastuti, Endah, Dimas Adrianto, D. A. N. (2017). Kajian Dampak Penggunaan Media Sosial Bagi Anak Dan Remaja. 